\title{
A novel method for modelling nonlinear dynamical systems applied to the Hodgkin-Huxley neuron Caitriona Boushel* and Paul Curran
}

\author{
Address: School of Electronic, Electrical and Mechanical Engineering, University College Dublin, Ireland \\ Email: Caitriona Boushel* - cboushel@ee.ucd.ie \\ * Corresponding author
}

from Seventeenth Annual Computational Neuroscience Meeting: CNS*2008

Portland, OR, USA. 19-24 July 2008

Published: II July 2008

BMC Neuroscience 2008, 9(SuppI I):P39 doi:I0.I I86/I47I-2202-9-SI-P39

This abstract is available from: http://www.biomedcentral.com/I47I-2202/9/SI/P39

(c) 2008 Boushel and Curran; licensee BioMed Central Ltd.

Two dynamical systems are considered equivalent if their bifurcation diagrams (or part of their bifurcation diagrams) are topologically equivalent. Hence, the two systems display the same bifurcation behaviour. In addition to this, we propose that the input-output behaviour of the systems and the behaviour of small networks of the systems will be qualitatively similar. To support this claim, a second order system, which is equivalent to the HodgkinHuxley $(\mathrm{HH})$ neuron, is presented. The $\mathrm{HH}$ neuron [1] is the standard biologically plausible model of the electrical activity in a neuron. It consists of four coupled nonlinear ordinary differential equations that relate the potential across the neuron's membrane to three ionic currents flowing through the membrane and an externally applied current. The second order system, with $u$ and $\mu$ as the bifurcation parameters,

$$
\begin{aligned}
& \dot{\mathrm{r}}=\mathrm{r}\left(\left(\sigma_{0}(\mu)+\tau_{0}(\mu) u-u^{2}\right)+\left(\sigma_{1}(\mu)+\tau_{1}(\mu) u\right) \mathrm{r}-\mathrm{r}^{2}\right) \\
& \dot{\phi}=\omega_{0}
\end{aligned}
$$

with $\mathrm{r} \geq 0, \phi \in[0,2 \pi]$ and $\sigma_{0}(\mu)=-\mu 2, \tau_{0}(\mu)=1-\mu, \sigma_{1}(\mu)$ $=-2 \mu$ and

$$
\tau_{1}(\mu)= \begin{cases}\frac{2 \mu_{2}}{u_{2}}, & \text { for } \mu \geq \mu_{2} \\ \frac{2 \mu+2 \sqrt{\left(\mu-\left(u_{2}-1\right)\right)\left(\mu-\mu_{2}\right)}}{u_{2}+\mu_{2}-\mu}, & \text { for } \mu \leq \mu_{2}\end{cases}
$$

can approximate the two-parameter bifurcation diagram of the HH neuron, with the input current (I) and the potassium current equilibrium potentials $\left(\mathrm{E}_{>K}\right)$ as the bifurcation parameters (see Fig. 1). It also reproduces much of the input-output behaviour of the HH neuron. When single input pulses are applied to the second order neuron and the HH neuron, both neurons switch from their stable equilibria to stable limit cycles and back again at the same time. When a continuous train of input pulses or a sinusoidal input are applied, both neurons oscillate

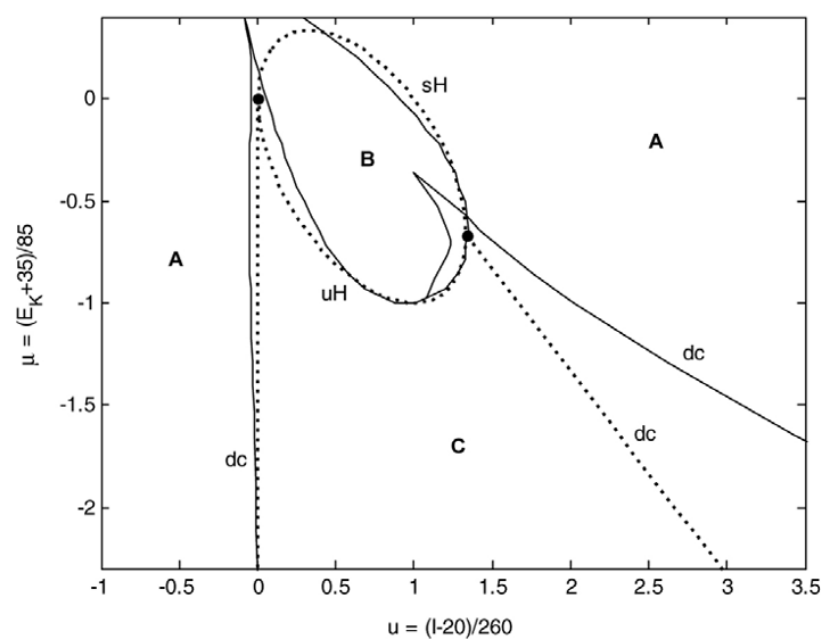

Figure I

Two-parameter bifurcation diagrams of the $\mathrm{HH}$ neuron (solid lines) and the second order neuron (dotted lines) in the $u-\mu$ parameter. The supercritical Hopf, subcritical Hopf and double limit cycle bifurcation curves are labelled $\mathrm{sH}, \mathrm{uH}$ and $\mathrm{dc}$. 

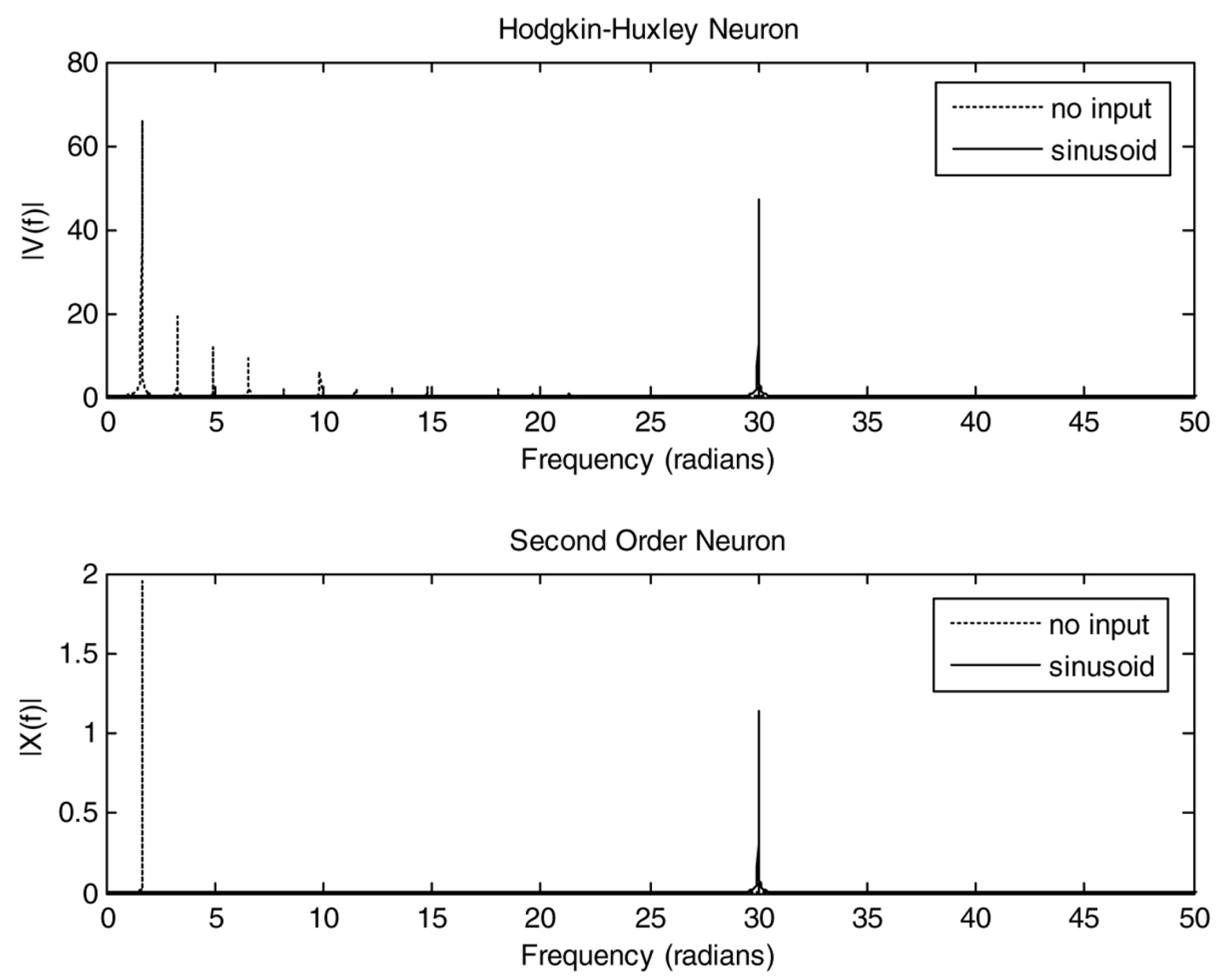

\section{Figure 2}

Frequency spectra of the $\mathrm{HH}$ neuron (upper plot) and the second order neuron (lower plot). The dotted spectra are with no input to the neurons and the solid spectra are with a continuous train of input pulses.

at the frequency of the input signal once its amplitude is large enough (see Fig. 2). In addition, the oscillations of two second order neurons synchronise when the neurons are coupled, replicating the behaviour of two coupled $\mathrm{HH}$ neurons. These results indicate that nonlinear dynamical systems, which have topologically equivalent bifurcation diagrams, will have qualitatively similar input-output behaviour and qualitatively similar network behaviour as well as the same bifurcation behaviour.

\section{References}

I. Hodgkin AL, Huxley AF: A quantitative description of membrane current and its application to conduction and excitation in nerve. J Physiol 1952, I 1 7:500-544.
Publish with BioMed Central and every scientist can read your work free of charge

"BioMed Central will be the most significant development for disseminating the results of biomedical research in our lifetime. "

Sir Paul Nurse, Cancer Research UK

Your research papers will be:

- available free of charge to the entire biomedical community

- peer reviewed and published immediately upon acceptance

- cited in PubMed and archived on PubMed Central

- yours - you keep the copyright

Submit your manuscript here:

http://www.biomedcentral.com/info/publishing_adv.asp 